\title{
Los privilegios rodados del Archivo General de la Administración Central de Alcalá de Henares
}

\author{
Maria Pia Senent
}

Estos cuatro privilegios rodados conservados en el Archivo General de la Administración Central de Alcalá de Henares pertenecen a una colección de pergaminos medievales que llegaron al A.G.A. formando parte de una serie de expedientes administrativos procedentes del Ministerio de Hacienda. En la actualidad son los documentos más antiguos del archivo, que por ser parte de unos expedientes encuentran justificada su presencia entre fondos contemporáneos.

Esta serie de pergaminos, conocida por los archiveros de Alcalá como los "pergaminos reales de Hacienda", son consecuencia de la desvinculación señorial del siglo $x \mid x$.

Los legisladores de Cádiz se enfrentaron con el problema del Régimen Señorial que desde la Edad Media diferenciaba señorios solariegos y señorios jurisdiccionales. En este sentido el Decreto del 6 de junio de 1811 dispuso la incorporación a la Nación de estos últimos. La legislación fue revisada en 1813 tratando de resolver el punto clave que era la obligatoriedad de la presentación de sus títulos por parte de los señores para diferenciar unos señorios de otros.

Durante el trienio liberal, se volvió a abordar el problema y la Ley del 3 de mayo de 1820, que interpretaba el Decreto del año 11 estableció la obligatoriedad de la presentación de los títulos.

El proceso terminó en 1837 con la Ley del 26 de agosto que arbitró una fórmula de compromiso al exigir tan sólo los títulos de aquellos señorios jurisdiccionales.

La colección de pergaminos de Alcalá encuentra su razón de ser dentro de este contexto. Los documentos llegaron al Ministerio de Hacienda y desde alli fueron transferidos al A.G.A. 
El grupo de documentación medieval del A.G.A. son 18 cartas plomadas en pergamino portadores de privilegios y mercedes reales concedidos a fines de la Edad Media. Todos ellos son entregas de señoríos jurisdiccionales por lo que fueron afectados por los decretos gaditanos y liberales del $x i x$. Sin embargo, no son los únicos ejemplares del archivo. Entre muchos de los expedientes de Hacienda encontramos otros documentos que por su tamaño permanecen dentro de las unidades documentales de las que forman parte.

Estas 18 cartas, y por tanto los cuatro privilegios rodados, se separaron de los expedientes con los que habian llegado al archivo y actualmente resulta difícil de recuperar su ubicación archivistica más correcta. Si bien, esto es un problema para su empleo como fuente para la historia del siglo pasado, tiene sus ventajas para aquellos que nos dedicamos a la historia medieval ya que están todos reunidos en una misma carpeta de fácil acceso y cuya única limitación seria la conservación.

Los privilegios de Alcalá son unas preciosas piezas documentales del siglo xIV. El más antiguo data del reinado de Fernando IV y los dos más modernos de tiempos de Juan I. Sin embargo, tres de los mismos son mercedes de Enrique II siendo las confirmaciones de su heredero lo que nos ha llegado.

Estos privilegios rodados están escritos en la letra canonizada típica de la documentación solemne del xiv que Terreros llamó «Gótica de privilegios" y que los actuales paleógrafos denominan "minúscula diplomática» cuya vida perdura desde su entrada en la Cancilleria Castellana con el Magister Hugo en tiempos del Emperador y llega hasta los Reyes Católicos. Escritos sobre pergamino tuvieron sello de plomo colgado de cintas de seda hoy perdidos, aunque por lo demás, su estado de conservación es excelente.

Esperamos que con este primer trabajo se den a conocer fondos de rivestros archivos hasta hoy poco conocidos y fundamentales para el conocimiento del Régimen Señorial de la Edad Media y su desarticulación en el siglo $x i x$. 
Los privilegios rodados del Archivo General de la Administración...

1302, mayo, 2 - Medina del Campo

Fernando IV, el Emplazado, concede a Ferrant Roys d'Amaya el Señorio de Aza, Santa Cruz de la Salceda y Montejo.

A.G.A. Sección de Hacienda, Colección de Pergaminos.

(Cristus. Alfa-Omega) En el nombre del Padre e del fijo e del Espiritu Santo, son tres personas distintas e un Dios, e de la bienaventurada Virgen Gloriosa Santa Maria, su madre, a quien nos tenemos por señora e avogada en todos nuestros fechos, por que es natural cosa que todo ome que bien faze / quiere que gelo lieven adelante e que se non olviden nin se pierda que commo quier que cause e nieguese el curso de la vida deste mundo, aquello es lo que finca en remenbranca por el del mundo e este bien es gaiyador de la su alma ante Dios. E por non ca/er en olvido lo mandaron los Reyes poner en escripto en los privilegios por que los otros que regnasen despues dellos e toviesen en so logar fuesen tenudos de guardar aquello e del osevar adelante confirmandolo por los privilegios. Por ende nos catan/do esto querenos que sepan, por este nuestro privilegio, los ommes que agora son e seran de aqui adelante, commo nos Don FERRANDO, por la gracia de Dios, Rey de Castiella, de Toledo, de Leó(n), de Gallizia, de Sevilla, de Cordova, de Murçia, de / Jah(e)n, del Algarbe e Señor de Molina. Por muchos serbiçios e buenos que vos. Ferrant Roys d'Amaya, me fecistes e me fazedes e por aver voluntad de vos facer mucho bien e mucha merced, e para que seades más bien honrado e non sigades vos nin vuestros herederos en ninguna e tengades con que más bien vos mantener e nos posades servir, e aviendo consejo e con otorgamiento de la Reina Donna Maria, mi madre, e del Ynfante Don Enriq(ue), mio tio e mío tutor, dobos a Aça e a / Santa Cruz de la Salçeda e a Montejo con todos los sus términos e con montes, con fuentes, con rios e con pastos e con entradas e con salidas con todas las demás pertenencias que a e debe aber. E otorgo vos que allades los sobredichos / logares e términos dellos libre e quito por juro de heredad para siempre jamás, para vos e para vuestros fijos e para vuestros nietos e para otros qualesquier que lo vuestro ovieren de heredar, para dar e bender e enpennar e canbear e enajenar e para facer dello e en ello todo lo que quisieredes / alli como de lo vuestro mismo salbo que non pobades faser ninguna destas cosas sobredichas con Eglesia nin con orden nin con ome de Religión nin de fuera de mio señorio nin que sea de mío serviçio sin mio mandado. $E$ vos do los sobredichos logares e sus términos con todos los pechos e de/rechos, martiniegas, yantares, portazgos e demás qui por qualquier paso alli de fecho como de derecho vos toquen e pertenescan e al señorio e propiedad de los sobredichos logares e sus términos. E retengo en estos mismos logares sobredichos para mi, moneda forera de siete / en siete años quando me la dieren los otros de la mi tierra e mineras de oro e de plata si las ay o las obiere daqui adelante e iustiçia si la vos non ficieredes quien yo gela mande conplir. E defiendo firmemente que ninguno non sea osado de vos yr nin de vos pasar contra esta / merced que vos fago en ninguna manera ca qualquier que lo fisiese avrá la mi yra e pecharme ya en coto de diez mil madaveries de la moneda nueva e a vos Ferrand Roys d'Amaya, el sobredicho, a quien vuestro vos tomese todo el daño e el menoscabo que por ende reçibiesedes doblados. / $\mathrm{E}$ yo dello mando que todabia se vos guarde e cumpla lo que en esta mía carta es mandado e a los míos adelantados merinos e demás ministros que alli vos lo fagan guardar e conplir. E otro si mando al ome a quien vos, el sobredicho Ferrand Roys, o por vos quien vuestra vos tovie/re requerades con esta nuestra carta o con traslado de ella, signado de escrivano público para que qualquier o qualesquier que la contrariaren en poco o en mucho que los enplaçe por ante nos e para que bengan e parezcan en la nuestra Corte fasta quinçe dias contados desde el en que los / enplaçare primeros siguientes, e por que esto sea firme e estable para siempre jamás, mandé despachar esta carta con mio sello de plomo. Fecho el pri- 
vilegio en Medina del Campo, çinco dias andados del mes de Mayo en la era de mil e trescientos e quarenta años. E nos, el sobredicho Rey Don FERRANDO, regnante e uno con la Reyna Doña COSTANÇA, mi muger, en Castiella, en Toledo, en Leó(n), en Gallizia, en Sevilla, en Cordova, en Murçia, en Jah(e)n. en Baeça, en Badalloz, en el Algarbe e en Molina, otorga/mos este privilegio e confirmamoslo.

El Infante Don Henriq(ue), tio del Rey ... Confirma, el Infante Don Joh(a)n, tio del Rey ... Confirma, el Infante Don Pedro, hermano del Rey ... Confirma, el Infante Don Felippe, hermano del Rey e Señor de Cabrera e de Riba? ... Confirma.

Don Gonçaluo, Arzobispo de Toledo, Primado de las Españas e Chanceller Mayor de Castiella ... Confirma, Don Frey Rod(ri)go Arzobispo de Santiago, Primado de las Españas e Chanceller del Regno de León ... Confirma, Don Amoravid. Arzobispo de Sevilla ... Confirma.

(Signo Rodado de la Corona de Castilla: Cruz Lisada con los castillos y los leones en los cuarterones) SIGNO DEL REY DON FERANDO. DON IOHAN (...) ALFEREZ CONFIRMA, (DON) (....) (MAYORDOMO DEL REY) - CONFIRMA.

\section{COLUMNA:}

Don Pedro, Obispo de Burgos

Confirma

Don Alvaro, Obispo de Palençia

Contirma

Don loh(a)n, Obispo de Osma

Contirma

Don Ferra(n)do, Obispo de Calahorra

Don Pasq(ua)l, Obispo de Cuenca

Confirma

Don S(e)v(er)ino, Obispo de Siguença

Confirma

Don Ferra(n)do, Obispo de Segovia

Confirma

Don P(er)o, Obispo de Avila

Don D(oming)o, Obispo de Plase(n)cia

Don Ferra(n)do, Obispo de Cartagena

La Iglesia de Alvarrasi(n)

Confirma

Confirma

Confirma

Don Ferra(n)do, Obispo de Córdova

Confirma

Logar

Don Gu(tierre), Obispo de Jah(e)n

Confirma

Don Frey P(er)o, Obispo de Cádiz

Confirma

Don Frey R(odrig)o, Obispo de Marruecos

Don Alema(n), Maestre de Calatrava

Contirma

Contirma

Confirma

\section{COLUMNA:}

Don Iohia)n, fijo del Infante Don Manuel, Adelantado Maior del Regno de Murçia

Don Alfon(so), fijo del Intante de Molina

Don Diago de Haro, Señor de Vizcaya

Don ioh(a)n Muñiz

Don loh(a)n Alfon(so) de Haro, Señor de los Cameros?

Don Ferran(do) P(ére)z de Guzmá(n)

Don Garçi Fer(rande)z de Villamayor, Adelantado Mayor de Castie$\| a$

Don Ferrarit Roys de Saldaña

Don Lope Rod(ri)g(ue)z de Villalobos

Don Roy Gil so hermano

Don Diago Gómez de Castañeda

Don Alfon(so) G(óme)z so hermano

Don Gu(tierre) Ferr(ande)z Martin

Don Gonçaluo d'Aguilar

Don P(er)o Enriq(ue)z de (...)

Don Lope de Mendoça

Confirma

Confirma

Confirma

Confirma

Contirma

Confirma

Confirma

Confirma

Confirma

Confirma

Confirma

Confirma

Confirma

Contirma

Confirma

Confirma 
Don Rod(ri)g(o) Alvar(e)z de Aça

Confirma

loh(a)n Rod(ri)g(ue)z de Roias

Confirma

III COLUMNA

Don Gonçaluo, Obispo de Leó(n)

Don Ferra(n)t Alvar(e)z, Electo de Olmedo

Don Alfon(so), Obispo de Astorga

Don P(er)o, Obispo de Çamora

Don Frey P(er)o, Obispo de Salama(n)ca

Don Alfon(so), Obispo de Çuidade

Don Alfon(so), Obispo de Coria

Don B(er)naldo, Obispo de Badalloz

Don Rod(ri)go, Obispo de Mondoñedo

Don P(er)o, Obispo de Orens

Don $\mathrm{loh}(a) n$, Obispo de Tuy e Notario Mayor del Regno de Leó(n)

Don Rod(ri)go, Obispo de Lugo

Don Ioh(a)n Ozorez, Maestre de la Orden de la Cavalleria de Sa(n-

tti(a)go

Don Gonçaluo P(ére)z, Maestre de la Orden de Alcántara

Confirma

Confirma

Confirma

Confirma

Confirma

Confirma

Confirma

Confirma

Confirma

Confirma

Confirma

Confirma

Confirma

Confirma

IV COLUMNA:

Don Sancho, fijo del Infante Don P(er)o

Don Ferrant Rod(ri)g(ue)z, Pertiguero de Sa(n)ti(a)go

Contirma

Don Pero Ponçe

Don Ferra(n)t P(ére)z so hermano

loh(a)n Ferr(ande)z, fijo del Deán de Sa(n)ti(a)go

Don Alfon(so) P(ére)z de Guzmán

Don Ferra(n)t Ferr(ande)z de Limia

Confirma

Confirma

Confirma

Confirma

Confirma

Confirma

Don Rod(ri)g(o) Alvar(e)z

Confirma

Don Arias Diaz

Don Diago Ramirez

Confirma

Confirma

Esteva(n) P(ére)z Froilán, Adelantado? Mayor en tierra de León ...

Contirma

(Debajo del Signo Rodado) Don (...) Gutierr(e)z, Justicia Mayor en Casa de Rey ... Confirma, Alvar Páez, Almirante Mayor de la Mar ... Confirma, Loppe P(ére)z, Alcalle por el Rey en Burgos e su Notario Mayor de Castiella ... Confirma.

Yo, Gonçaluo M(artine)z de Peñafiel, lo escrivi por mandado del Rey en el año octavo? que el Rey Sobredicho reinó. (Rúbrica)

Pero Lope Pérez.

1377, noviembre, 2 - Burgos

Enrique II concede a Gonzalo Diaz Carrillo las Salinas de Espartinas.

A.G.A. Sección de Hacienda, Colección de Pergaminos. les.)

(E) documento comienza con una miniatura que representa al rey con los atributos rea-

En el nombre de Dios Padre e Fijo e Espiritu Santo que son tres personas e un Dios verdadero que bive e regna por siempre jamás, e de la bien aventurada Virgen gloriosa Santa MARIA su madre a quien nos te/nemos por señora $\theta$ por abogada en 
todos nuestros fechos e a onra e a servicio de todos los Santos de la Corte Celestial e qual por su piedat nos quiso ensalçar en detrimiento de los sus enemigos / e nos escogó por juez de su pueblo porque podiesemos onrar e ensalçar e engrandeçer los sus reinos e los defender e mantener en paz e en justicia. E porque todas las cosas que Dios / en este mundo fizo nacer naçer e feneçer quando el tiene por bien e quanto (resta de) vida en este mundo todavia a su tiempo en su curso sabido. E non finca otra cosa que fin non aya salvo Dios que nunca ovo comienço nin avrá fin. E a semejança / del ordenó los ángeles de la Corte Celestial e como quier que quiso que oviesen comienço pero no que oviesen fin mas que durasen por sienpre. $\mathrm{E}$ asi como él es duradero asi quiso quel su regno durase para sienpre. E por ende todos los reyes se de/ven menbrar de aquel regno a do an de yr a dar razón de lo que Dios en este mundo les encomendó e por quien regnan e cuyo lugar tienen por lo qual son tenudos de fezer limosna por el su amor e aún porque perteneçen al estado do los / reyes e a la su realeza e de enobleçer e onrar e previligiar a los su vasallos que bien e lealmente le sirven heredándolos en sus regnos. $E$ por ende queremos que sepan todos los que agora son e serán de aqui adelante commo nos / Don ENRIQUE, por la gracia de Dios, Rey de Castiella, de León, de Toledo, de Galiçia, de Sevilla, de Córdova, de Murcia, de Jah(e)n, del Algarbe, de Algezira e Señor de Molina, en uno con la reina Doña JUANA, mi muger, e con / el infante Don JUAN, mio fijo primero, heredero en Castiella e en León, por fazer bien e merced a vos Gonçalo Diaz Carriello, nuestro vasallo por muchos (servicios) e bonos que nos / aves fecho e fazes desde cada día (damos) nos por juro de heredad, para sienpre jamás, en las salinas de Espartinas cinco mil madaveries desta moneda que so agora husa que fazen / diez dineros novenos de madaveri, los quales dicho cinco mil madaveries (nos damos) en la moneda que dicha es para vos e para vuestros fijos e nietos e para qualquier otros vuestros herederos (e vuestros) descendientes para sienpre jamás / para vender e enpeñar e enagenar e dar e trocar e canbiar e facer dellos e en ellos e en parte dellos todo lo que vos quisiéredes o qualquier o qualesquier de los vuestros herederos que lo vuestro ovieren de aver e de heredar. E el que / lo por vos o por vuestros herederos o por qualquier dellos los oviere de aver e recabdar en qualquier manera e sobresto mandamos a qualquier o qualesquier que cogen o ayan de coger o de recabdar en renta o en fialdat o en otra / manera qualquier las dichas salinas de Espartinas agora e de aqui adelante de cada año para sienpre jamás que recabden e fegan recadar a vos el dicho Gonçalo Diaz e a vuestros herederos en la manera que dicho es con los dichos çinco/mil madaveries. E mandamos que vos non demanden otra nuestra carta mandadera de cada año sobresta razón. Ca con el traslado de nuestro privilegio signado de escrivano público e con carta de pago de vos el dicho Gonçalo Díaz / o de vuestros herederos o del que lo vuestro oviere de aver e de heredar, mandamos que los sean reçibidos en cuenta de cada año e si lo asi fazer non quisieren mandamos a los alcalles, jurados, juezes, justicias, merinos, aguasiles e otros / oficiales qualesquier que sean de todas las cibdades e villas e logares de (nuestros) regnos que agora son e serán de aquí adelante e qualquier o qualesquier dellos que este nuestro previlegio fuere mostrado o el traslado del signado / como dicho es que prendan e tomen e fagan prender e tomar a los cogedores o arrendadores o recabdadores de las salinas todos sus bienes asi muebles commo rayzes do quier que fallaren e los vendan / luego asi commo por el nuestro aver en manera que entregan a vos el dicho Gonçalo Diaz o al que lo enviare a recabdar por vos o a vuestros herederos o al que lo vuestro oviere de aver o de heredar o al que lo oviere de recabdar por ellos / con los dicho cinco mil madaveries en la manera que dicha es, dende adelante de cada año por sienpre jamás, segunt sobredicho es. E si bienes non les fallaren en que prender, que les prendan los cuerpos e que los tengan presos e bien recabdados e los non den sueltos nin fiados fasta que den e paguen a vos el dicho Gonçalo Diaz o al que lo oviere de recabdar por vos o a vuestros herederos o al que lo vuestro oviere de aver e de 
heredar para sienpre jamás los dichos / cinco mil madaveries. E los unos nin los otros non fagades ende al por ninguna manera so pena de la nuestra merced e de mil madaveries desta moneda husual a cada uno e demás por qualquier o qualeaquier que fincan de lo asi complir. Mandamos / al omme que este nuestro previlegio mostrare o el traslado del signado commo dicho es que vos enplazen que parescades ante nos do quier que seamos del dia que vos enplazaren o quince dias primeros siguientes so la dicha pena / a cada uno a dezir por qual razón non conprides nuestro mandado. E de commo este nuestro previlegio vos fuere mostrado e los unos e los otros lo complieredes. Mandamos so la dicha pena a qualquier escrivano público que para esto fuere llamado que de ende al que / nos lo mostrare testimonio signado con su signo por que nos sepamos en commo cunpludes nuestro mandado. Dado el previlegio en la cibdad de Burgis, a dos dias de Novienbre, era de mil e quatrocientos quince años. E nos el sobredicho rey / Don ENRIQUE reinante en uno con la reina Doña JUANA, mi muger, e con el infante Don JUAN, mio fijo primero, heredero en Castiella, en Leó(n), en Toledo, en Galizia, / en Sevilla, en Córdova, en Murçia, en Jahen, en Baeça, en Badajoz, en el Algarbe, en Algezira, en Molina, otorgamos este previlegio / e confirmamoslo.

(Rúbrica) Yo, el Rey (Rúbrica)

El muy noble infante Don JUAN, fijo del muy noble e muy poderoso e bien aventurado Rey Don Enriq(ue), primero heredero en los reinos de Castiella e de León Confirma.

Don Sanch(o), hermano del Rey, Conde de Albuq(ue)rq(ue), Señor de Haro e de Ledesma e su Alferez Mayor del dicho Señor ... Confirma.

Don Alfons(o), fijo del Rey, Conde de (Norena) e Señor de Ribera e de Cabrera ... Confirma.

Don Alfons(o), fijo del Infante Don Pedro de Aragón, Marqués de Villena e Conde de Ribagorta e de Denia, vasallo del Rey ... Confirma.

Don Ferrando, Arzobispo de Sevilla ... Confirma.

Don Gómez, Arzobispo de Toledo, Primado de las Españas, Chanceller Mayor del Rey ... Confirma.

Don Rod(ri)go, Arzobispo de Santiago, Capellán Mayor del Rey, Chanceller e Notario Mayor del Regno de Leó(n) ... Confirma.

(Signo Rodado inacabado, solo aparece el trazado del miniaturista y el centro del signo dividido en cuatro cuarterones con dos castillos y dos leones, escudo de la Corona de Castilla.)

\section{COLUMNA:}

Don Domi(n)go, Obispo de Burgos

Confirma

Don Gutierre, Obispo de Palencia

Confirma

Don Alfon(so), Obispo de Calahorra

Don Joh(a)n, Obispo de Osma

Don Joh(a)n, Obispo de Sigue(n)za

Don Obispo de Cuenca

Don Joh(a)n, Obispo de Segovia

Don Obispo de Avila

Don Frey Joh(a)n G(arcia), Obispo de Plasencia

Don Alton(so), Obispo de Córdova

Confirma

Confirma

Confirma

Confirma

Confirma

Confirma

Confirma

Don Nicolás, Obispo de Cartagena

Confirma

Don Frey Gonçalo, Obispo de Cádiz 
Don Ferrando Ozores, Maestre de la Cavalleria de la Orden de Santiago

Don P(er)o Moñiz, Maestre de la Orden de Calatrava

Don Ruy Diaz de Vega Maestre de la Orden de Alcanta...............

Don Prior de la Orden de Sant Joh(a)n

Confirma

Confirma

Confirma

Confirma

\section{COLUMNA:}

Don Joh(a)n Ramirez de Orellano, Señor de los Cameros, Vasallo del Rey

Don Joh(a)n M(artine)z de Luna, Vasallo del Rey

Don Joh(a)n Alfon(so) de Haro

Don Joh(a)n R(amire)z de Villalobos

Don G(onçal)o Gómez de Asturias

Don G(onçal)o F(e)rr(ande)z Ma(n)riq(ue)

Don Rod(ri)go Ma(n)riq(ue), so hermano

Don Beltrán de Gomara?

Don Ferr(an)te Alvarez, Señor de Valdecorneja y de Oropesa......

Don Ferr(an)t S(uárez) de Tovar, Adelantado Mayor del Rey ..........

Don Ferrant $P($ ére $) z$ de Ayala

Don $P(e r) o ~ F(e) r r(a n d e) z$ de Velasco, Camarero Mayor del Rey .....

Confirma

Confirma

Confirma

Confirma

Confirma

Confirma

Confirma

Confirma

Confirma

Confirma

Confirma

Confirma

III COLUMNA:

Don Frey P(er)o, Obispo de León

Don Alfon(so), Obispo de Oviedo

Don M(artin), Obispo de Astorga

Contirma

Don M(artín), Obispo de Çamora

Confirma

Don Alfon(so), Obispo de Salamanca, Notario Mayor de Andalucia

Don Alfon(so), Obispo de Cibdat $R(e a) l$

Don Obispo de Coria

Don Obispo de Badajoz

Confirma

Don Joh(a)n, Obispo de Tuy

Don Joh(a)n, Obispo de Orens

Don Pedro, Obispo de Me(n)doñedo

Don Joh(a)n, Obispo de Lugo

Confirma

Confirma

Contirma

Confirma

Contirma

Confirma

Contirma

Confirma

IV COLUMNA:

Don Pedro, Sobrino del Rey, Conde de Trastámara

Confirma

Don P(er)o Ponçe de Leó(n), Señor de Marchena

Confirma

Don Joh(a)n Alfon(so) de Guzmá(n), Conde de Niebla

Don Ramir(o) N(úñe)z de Guzmá(n)

Confirma

Confirma

Don Gonçalo Núño)z de Guzmá(n)

Confirma

Don $M($ artin) F(e)rr(ande)z de Guzmá(n)

Confirma

Don G(onçal)o F(e)rr(ande)z, Señor de Aguilar

Confirma

(Debajo del Signo Rodado aparecen cinco columnas más de confirmantes.)

1 COLUMNA:

Don P(er)o Manriq(ue), Adelantado Mayor de Castiella

Confirma

II COLUMNA: 
Don Joh(a)n S(uáre)z Manuel, Conde de Carrión, Adelantado Mayor del Regno de Murçia ....................................................................

Don Bernalt de Baerne, Conde de Medina Celi ............................ Confirma

III COLUMNA:

Joh(a)n N(úñe)z de Villazán, Justicia Mayor del Rey

Confirma

Diego López Pacheco, Notario Mayor de Castiella....

Confirma

Diego Gómez de Toledo, Notario Mayor del Regno de Toledo ....... Confirma

IV COLUMNA:

P(er)o Suárez de Q(ui)ñones, Adelantado Mayor de la Tierra de

Leó(n) e de Escuras

P(er)o Roys Sarmie(n)to, Adelantado Mayor de Galizia

Confirma

Contirma

$\checkmark$ COLUMNA:

Don Alfon(so) F(e)rr(ande)z de Mo(n)temayor, Adelantado Mayor de la Frontera

Confirma

1379, Agosto, Burgos

Juan I de Castilla confirma un privilegio rodado de Enrique II otorgando a Juan Martínez de Rojas todas las rentas de Monzón, Valdespino, Cobo y Cavia y los pechos de la juderia de Medina de Pomar.

A.G.A. Sección de Hacienda, Colección de Pergaminos.

[E]n el nonbre de DIOS Padre e Fijo e Espiritu Santo que son tres personas e un Dios verdadero que bive e regna por siempre jamás e dela bien aventurada Virgen gloriosa Santa MARIA su madre aquien nos te/nemos por Sennora e por avogada en todos nuestros fechos. E a onra e a servicio de todos los Sanctos de la Corte Celestial queremos que sepan por este nuestro privillegio todos los ommes que agora son e serán daqui adelante, commo Nos Don JOAN por la Gracia de Dios Rey de CastieIla, de Toledo, de Leon, de Gallisia, de Sevilla, de Córdova, de Murcia, de Jahle)n, del Algar/be, de Algesira e Señor de Lara e de Viscaya e de Molina, regnante en uno con la Regna Donna LEONOR mi mujer vimos un privillegio del Rey Don ENRIQUE nuestro padre que Dios perdone escripto/ en pergamino de cuero e rodado e seellado con su seello de plomo colgado, fecho en esta guisa. En el nonbre de DIOS Padre e Fijo e Espiritu Santo que son tres personas/ e un DIOS verdadero que bive e regna por sienpre jamás. E de la bien aventurada Virgen gloriosa Santa MARIA su madre aquien nos tenemos por Sennora e por avogada en/ todos nuestros fechos. E a onra e a servicio de todos los Santos de la Corte Celestial porque entre todas las otras cosas que son dadas a los Reyes, les es dado de faser gracia e merced a sennaladamilente do se demanda con derecho e con rason en el Rey quela fase ha de catar en ella tres cosas la primera que merçed es aquella que le demanda, la segunda que es el pro o el danno que ende le puede ve/nir sy la fisiere. La tercera que logar es aquel en quen ha de faser la merced e como es esta merced. E por ende Nos estando todo esto queremos que sepan por este nuestro privillegio todos los ommes que agora son o serán daqui adelante como Nos Don ENRIQUE/ por la Gracia de DIOS Rey de Castiella, de Toledo, de $L e o(n)$, de Gallisia, de Sevilla, de Córdova, de Mu(r)çia, de Jah(e)n, del Algarbe, de Algesira e Sennor de Molina, regnante en uno con la Regna Donna JUANA mi mujer e con el Infante Don JOAN/ nuestro fijo primero heredero en Castiella e en Leon he [abiendol Nos de los altos ser- 
vicios leales e buenos que Vos Don Joh(a)n M(artine)z de Rojas fijo de Sancho Sa/njchez de Rojas. Nos avedes fecho e fasedes/ de cada dia despues aca que sedes en nuestro servicio e en la nuestra merçed e començastes de Nos servir quando Vos [...] dello [...] porque valais mas e seades mas onrado Vos e los de vuestro linaie e avedes manera de/ lo pasar sienpre bien en la nuestra meçet. E commo quier quen nuestro coraçon tengamos propuesto devos faser muchas e altas mercedes por ello. Damos vos todas las rentas e pechos e derechos de Mo(n)çon e de Valdespina e de Cobo e de Cavia ansy servicios e mo/nedas commo alcavalas e terçias e otros pechos e tributos qualesquier foreros e non foreros usados e por usar e pedidos e tributos e avades que en qualquier manera [...] de pecho que todos los pecheros de los dichos logares de Mo(n)çon de Valdespina e de/ Cobo e de Cavia, Nos an adar este anno e de aqui adelante de los que dichos son e en otra manera qualquier asy los que agora y son pobladores e moradores commo de todos los otros que y poblaren e moraren de aqui adelante en los dichos logares e en cada uno dellos/. E estos dichos pechos e derechos de los dichos logares vos damos en enmienda de los veynte mil e trescienios e treynta marevedies de que Nos vos ovimos fecho merçet que oviesedes de cada anno por juro de heredad en esta manera. En la caloça del pecho de/ los judios de la juderia de Medina de Pomar los dosemil e tresientos treynta maravedies e en las tercias de la albadia de Fromi(s)sta los ocho mil maravedies e los non podiedes aver nin cobrar dende por quanto Nos fasemos merçet de la dicha villa de Medina con todas sus rentas e pechos e dere/chos e con la caloça del dicho pecho de los dichos judios a por Ferr(an)do de Velasco nuestro camarero mayor. E ansy tomamos las terçias de la dicha albadia que son enel Obispado de Burgos para las arrivadas(?) de las nuestras flotas. E todo esto segunt dicho es vos damos por/ la dicha enmienda por juro de heredad para siempre jamas para vos e para vuestros herederos para vender e enpennar e dar e trocar e cambiar e enajenar e para faser dello e en ello todo lo que vos quisieredes segunt que farades e podades faser delo vuestro mesmo propio/. E que tenemos por bien que ninguna nin alguna destas cosas que dichas son antes non podades faser con Yglesia nin con orden nin con otra persona alguna de religión nin de fuera de nuestro Sennorio que estuviesen en nuestro servicio sin nuestra licencia e sin/ nuestro mandado. E sobre esto mandamos a todos los pecheros de los dichos logares de Monçon e de Valdespina e de Cobo e de Cavia que agora y son o seran daqui adelante que recadan e fagan recadir a vos el dicho Joh(a)n $M$ (artine) $z$ e al quanto ovier de recabdar por vos/ deaqui adelante con todas las rentas e pechos e derechos sobre dichos e con todos los dichos tributos e con cada uno de ellos de cada anno sugunt que mejor e mas conplidamiente e ayan de recadir fasta aqui con ellos a Nos e a los otros Reyes nuestros/ antecesores e a los otros qualesquier que fasta aqui lo ovieron de aver de recabdir e Nos los dan e pagan ovieren e pagaren de cada anno los otros de la nuestra tierra bien e complidamiente en guisa que vos non mengüe ende ninguna cosa e non a otro allguno. E defendemos a los nuestros cogedores e recabdadores $e$ arrendadores e pesquisidores e enpadronadores de las dichas monedas e servicios e alcavalas e terçias e delas otras dichas rentas e pechos e derechos e tributos sobredichos que agora y son o seran daqui aldelante e a qualquier o qualesquier dellos que este nuestro privillegio fuere mostrado o el traslado del signado de escrivano publico que non pidan nin demanden nin cojan nin recabden los dichos servicios e monedas e terçias e alcavalas nin los dichos pechos e tri/butos que dichos son nin alguno dellos a los dichos pecheros de los dichos logares nin a ninguno dellos nin los enpadronen en ellos nin en alguno dellos nin los fagan otras premias (?) nin afincamientos algunos sobre ello agora nin daqui adelante otrosi en los dil chos pecheros de los dichos logares nin alguno dellos non sean tenudos de recadir con ellos a Nos nin a los dichos nuestros cogedores e arrendadores e pesquisidores nin alguno dellos agora nin daqui adelante nin con alguno dellos nin gelos dar nin pagar nin vayan a sus enplasamientos sobre ello nin cayan en pena alguna sobre 
esta rason mas que recurran con ellos de cada anno avos el dicho Joh(a)n M(artine)z o a vuestro mandado a otro e a los dichos vuestros herederos e non a otro alguno segunt dicho es. E que los nuestros Chan/celleres e notarios e escrivanos e otros oficiales qualesquier de la nuestra Corte que non libren nin seellen a los nuestros seellos ningunas nin algunas cartas para que gelo demanden que los salven e fagan salvar de cada anno asy en las condiciones de las rentas/ quando se fisieren algunas de las nuestras rentas en la nuestra Corte e Nos mandamos coger en cualquier manera en la nuestra tierra e que nuestros contadores de los nuestros libros que [...] $e$ saquen de los dichos nuestros libros estos dichos pecheros de los dichos loga/res porque vos son bien guardada de aqui adelante esta merçet que Nos vos fasemos. Otrosi que los dichos nuestros cogedores e recabdadores e arrendadores que ovieren de aver las dichas rentas e pechos e derechos en las merindades de Burueva y de Condemuln(n)o e de Monçon o en otras partes qualesquier de los nuestros Regnos agora e daqui adelante que les non fagan demanda nin premura nin afincamiento alguno sobre esta rason a los dichos pecheros de los dichos logares nin alguno dellos nin ellos nin alguno dellos nin ellos nin algund dellos non sean tenudos a ellos nin a los recadir con ello nin gelo dar nin pagar salvo a vos el dicho Joh(a)n $M$ (artine)z e a los dichos vuestros herederos o al que to ovier de recabdar por vos o por ellos en la manera que dicha es que les non prenden in tomen nin enbarguen ningunal cosa de lo suyo por esta rason. Porque tenemos por bien que sy en las dichas rentas e pechos e derechos e tributos de los dichos logares montaren mas de los dichos veynte mil e tresientos e treynta maravedies de Nos vos fasemos merced gelo tecabden para Nos/ los nuestros cogedores e recabdadores e arrendadores e sy en las dichas rentas e pechos e derechos e tributos sobre dichos de los dichos logares montaren menos de los dichos veynte mil e tresientos e treinta maravedies de que Nos Vos fasemos merced que Vos los cun/plan e den e pagen los nuestros thesoreros e los nuestros contadores e cogedores e recabdadores e arrendadores o qualquier dellos de los qualesquier maravedies de las nuestras rentas e pechos e derechos e que Nos ovreremos de aver de cada anno en los logares de las dichas meryndades de/ Burueba e de Candemunno e de Monçon o en qualquier dellas. $E$ los unos nin los otros non fagan ende al por ninguna manera sopena de nuestra merced e de mil maravedies de la buena moneda a cada un por cada (...) para la nuestra Cámara. E Nos mandamos al adelantado/ que por Nos fuer en Castiella agora e daqui adelante e al merino o merinos que por Nos o por el andudieren en el dicho adelantamiento e a todos los alcalles e merinos, jurados, jueses, justicias, merinos, aguasiles e otros oficiales qualesquier de todas las cibdades e/ villas e logares de nuestros Regnos o qualquier o qualesquier dellos que este nuestro privillegio vieren o el traslado del signado de escrivano publico que gelo non consientan e que prenden por la pena aquellos que cayeren en ella e la guarden para faser della lo que Nos man/daremos e defendemos firmemiente que alguno nin algunos non sea osados de Vos yr nin pasar contra este nuestro privillegio nin contra lo que en el dise para Vos to quebrantar nin menguar en algunt tienpo por alguna manera en qualquier o qualesquier que to fisieren/ e avrian nuestra yra e pecharnos an por cada (...) la dicha pena e a Vos el dicho Joh(a)n M(artine)z e a los dichos vuestros herederos e a quien lo vuestro Vos (oviese de aver e) toviese todo el danno e menoscabo que por ende rescibieredes doblado e desto vos mandamos dar este nuestro pref villegio escripto en pergamino de cuero rodado e seellado con nuestro seello de plomo colgado. Fecho el privillegio en la muy noble Cibdad de Burgos primer dia de setiembre de mil e quatrocientos e trese annos. E agora el dicho Joh(a)n M(artine)z de Rojas nuestro va/sallo e nuestro Alcalle Mayor de los fijosdalgo pidonos merced que lo firmasemos la dicha merced de mano que el dicho Rey Don $E(n)$ rique nuestro padre, que Dios perdone, le fiso [el sobredicho Rey] Don [Juan] Regnante en uno con la Regna Donna/Leonor mi mujer por facer bien e merced al dicho Joh(a)n M(artine)z de Rojas tovimoslo por bien e confirmamosle la dicha merced (...) se contiene 
y segunt que le fue guardada en tiempo del Rey Don $E(n)$ rique nuestro padre, que Dios perdone, e defendemos tirmemiente que ninguno sin algunos non sean osados de le yr nin pasar contra la carta qualquier que lo fisiese pecharme la pena so bien dicha por cada (...) e al dicho Joh(a)n M(artin)ez de Rojas o a su herederos o a quien su los toviere todos los dannos e menoscabos que por ende dello e demas a los sus cuerpos e a lo que oviesen Nos tomaremos por ello e desto le mandamos dar este nuestro privillegio rodado e seelado con nuestro seello de plomo colgado. Fecho en las Cortes de la muy noble Cibdad de Burgos seis dias de agosto de mil e quatrocientos e diez e siete annos.

(Rúbrica) Nos el Rey (Rúbrica)

El Infante Don Denis, fijo del Rey de Portogal, Sennor de Alba de Tormes, vasallo del Rey

Don Alfon(so), Conde de Norena (?), hermano del Rey

Don Alfon(so), fijo del Infante Don Pedro de Arago(n), Marqués de Villena, Conde de Ribagorda y de Denia, vasallo del Rey

Don Beltra(n) de Elaquin Condestable de (Fran(cia), vasallo del Rey

(Encima del Signo Rodado): Don Pedro Arzobispo de Toledo Primado de las Espannas

Confirma

Confirma

Confirma

Contirma

Confirma

Signo Rodado de la Corona de Castilla. En los cuarterones los Castillos y los Leones. Leyenda.

\section{COLUMNA:}

Don Pedro, Arzobispo de Sevilla

Don Joh(a)n, Obispo de Siguença, Chanceller Mayor del Rey ........

Don Domi(n)go, Obispo de Burgos

Don Obispo de Palencia

Don Go(n)zalo, Obispo de Calahorra

Don

Obispo de Osma

Don Yugo, Obispo de Segovia

Don Alfon(so), Obispo de Avila

Don Nicolás, Obispo de Cuenca

Don Pedro, Obispo de Plasencia

Don Pedro, Obispo de Córdoba ....

Don Nicolas, Obispo de Cartagena

Don Joh(a)n, Obispo de Jahe(n)

Don Joh(a)n, Obispo de Cadis
Contirma

Confirma

Confirma

Confirma

Confirma

Confirma

Confirma

Confirma

Confirma

Confirma

Confirma

Confirma

Confirma

Confirma

\section{COLUMNA}

Don Joh(a)n Sa(n)chez Manuel, Conde de Carrio(n), Adelantado

Mayor del Regno de Mu(r)cia

Don Bernal de Bearne Conde de Medina, vasallo del Rey

Don Diego Gómez Ma(n)riq(ue)

Contirma

Don Joh(a)n Rodrig(u)ez de Castan(n)eda

Confirma

Don Joh(a)n Rodrig(u)ez de Villalobos

Confirma

Don Joh(a)m Sarmiento D'Orellana, Sennor de los Cameros, vasallo del Rey

Confirma

Don Beltra(n) de Guevara

Confirma

Confirma

Don Sa(n)cho $F(e) r r(a n d e) z$ de Tovar, Guarda Mayor del Rey

Don Arnao, Sennor de Villalpa(n)do, vasallo del Rey

Confirma

Don Joh(a)n M(artine)z de Luna, vasallo del Rey

Confirma

Don Nun(n)o Nun(n)ez D'Aça

Confirma 
Los privilegios rodados del Archivo General de ia Administración...

Don Nun(n)o Alvarez D'Aça

Confirma

III COLUMNA:

Don Rodrigo, Arzobispo de Santiago, Capellán Mayor del Rey, No-

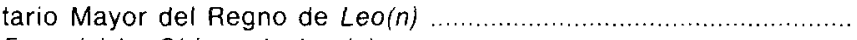

Ferna(n)do, Obispo de Leo(n)

Don Gut(ierr)e, Obispo de Oviedo

Don Alfon(so), Obispo de Astorga

Confirma

Confirma

Don Alvaro, Obispo de Camora

Confirma

Don Alfon(so), Obispo de Salamanca

Confirma

Eon Alfon(so) Obispo de Cibdad Rod(ri)go

Don Ferna(n)do, Obispo de Coria

Confirma

Confirma

Confirma

Don Ferna(n)do, Obispo de Coria

Confirma

Don Ferna(n)do, Obispo de Badajoz

Don Francisco, Obispo de Mo(n)don(n)edo

Don Joh(a)n, Obispo de Tuy

Don G(onzal)o, Obispo de Orens(e)

Confirma

Confirma

Confirma

Confirma

Don Pedro, Obispo de Lugo

Confirma

IV COLUMNA:

Don Fad(ri)que, Duque de Benave(n)te, hermano del Rey

Confirma

Don P(er)o, Primo del Rey, Conde de Trastamara e de la Casa de

Sarria

Don Joh(a)n Alfon(s)o de Guzman, Conde de Niebla

Confirma

Contirma

Don P(er)o Ponce de Leó(n)

Don Alvar P(ére)z de Guzman, Aguasil Mayor de Sevilla

Don Ramiro Nun(n)ez de Guzma(n)

Confirma

Confirma

Confirma

Don G(onzallo Nun(n)ez de Guzma(n)

Contirma

Don Pedro de Villes, Conde de Ribadeo, vasallo del Rey ............. Confirma

Don Alfon(s)o Tellez Giro(n)

Don P(er)o Alfon(so) Giro(n)

Don G(onzal)o F(er)rr(ande)z, Sennor de Aguilar

Confirma

Contirma

Contirma

(Por debajo del signo rodado.)

\section{COLUMNA:}

Don P(er)o F(e)rr(ande)z de Velasco, Camarero Mayor del Rey .... Don P(er)o Ma(n)riq(ue), Adelantado Mayor de Castilla

Confirma

Confirma

\section{COLUMNA:}

Don Joh(a)n Nun(n)ez de Villazan, Justicia Mayor de la Casa del

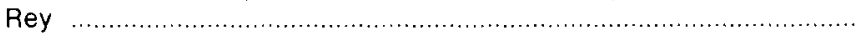
Don Ferra(n)te Sa(n)chez de Tovar, Almirante Mayor de la Mar ... Diego Lop(e)z Pacheco, Notario Mayor de Castiella

Don P(er)o Suares de Toledo. Adelantado Mayor de Toledo e Notario Mayor del Regno de Toledo

Don P(er)o Suares de Guzma(n), Notario Mayor de Andaluzia .......

Confirma

Confirma

Confirma

Confirma

Confirma

III COLUMNA:

Don Ferna(n)do Suarez, Maestre de la Orden de la Cavalleria de Santiago Don Diego Martinez, Maestre de Alcántara 


\title{
IV COLUMNA:
}

Don P(er)o Min(n)iz, Maestre de la Orden de la Cavalleria de Calatrava e Adelantado Mayor de la Frontera

El Prior de Sant Joh(a)n

Confirma

Confirma

Confirma

Don Pedro Obispo de Plasencia, Notario Mayor de los Previllegios Rodados 10 mandó dar en el día primero que el Rey sobredicho Don Joh(a)n regnó e se coronó Rey de Castiella.

P(er)o Loys F(e)rr(ande)z escrivano del Rey lo fizo escrivir.

\author{
(Rúbrica) Yo el Rey (Rúbrica) \\ Firma ilegible \\ (Rúbrica) Loys Ferrandez (Rúbrica)
}

1379, Agosto, 25 - Burgos

Juan I confirma un privilegio de Enrique II a Juan González de Avellaneda concediéndole el Señorio de Iscar.

A.G.A. Sección de Hacienda, Colección de Pergaminos.

(Christus - dentro de un E capital) En el nombre de la SANTISIMA Trinidad de Dios Todopoderoso, principio e fin de todas las cosas, que bien regna sin principio ni fin, e de la bien aventurada Santa MARIA, madre de nuestro / Señor Jesu Christo, a quien nos tenemos por sennora e por abogada, ca honra e gloria del bien aventurado Apostol Santiago, patrón e guia de los Relyes de Castiella e de Leó(n), e de los demás Santos e Santas de la Corte Celestial. Por que es cosa conveniente e reçonable que los Reyes e Principes fagan gracia e ' mercedes a los sus suditos especialmente a aquellos que bien e lealmente les sirben e para ello deben acatar tres cosas que la una debe ser que merced es la que le face, la otra es a quien y por qué raçón se la face e como gela me/rece e la otra si es o puede ser en provecho o en daño del Rey o de Príncipe que la face o de los subcesores. E nos considerando e estando cierto de todo ésto e de los muchos e buenos e especiales serviçios que vos Joh(an)n Go(nzale)z de Abellane/da. Caudillo Mayor de los nuestros esduceros, nos fazedes e nos habedes fecho antes de agora e los que estamos cierto nos faredes en adelante queremos que sepan por este previllejio todos los omes que agora son e que serán de aqui adelante como / nos Don IOAN, por la gracia de Dios, Rey de Castiella, de Leó(n), de Toledo, de Gallizia, de Sevilla, de Córdiva, de $M u(r) c ̧ i a$, de Jahe(n), del Algarbe, de Algezira e Señor de Vizcaya e de Molina, en uno con la Reina Doña LEONOR, mi / muger, vimos una carta de previllejio por nos a vos dada, escrita en pergamino de cuero e sellada con nuestro sello de plomo colgado, fecha en esta guisa: En el nombre de Dios Padre e Fijo e Espiritu Santo que son tres Personas e un Dios verdadero, poderoso, principio e fin de todas las cosas e que bive e regna por sienpre jamás, e de la vienaventurada Virgen Santa Maria, su madre, quien nos havemos e tenemos por senno/ra e por avogada en todos nuestros fechos e a onra e serviçio de todos los demás Santos de la Corte $\mathrm{Ce}$ lestial, queremos que sepan por este nuestro previllegio o por su traslado signado de escrivano público, de todos los que agora son e serán de aqui adelante, como nos Don / Jua(n) por la gracia de Dios Rey de Castiella, de Leó(n), de Toledo, de 
Gallizia, de Sevilla, De Córdova, de $M(u r) c ̧ i a$, de Jahe(n), del Algarbe, de Algezira e Señor de Vizcaya e de Molina, vimos un prebillejio del Rey Don Enriq(ue), nuestro padre, que Dios perdone, escripto en pergamino de / cuero, rodado e sellado con su sello de plomo colgado en filos de seda de colores en esta guisa: En el nombre de Dios Padre e Fijo e Espiritu Santo, que son tres Personas e un Dios verdadero, que bien regna por sienpre jamás, e de la bienaventurada Virgen / gloriosa Santa Maria, su madre, a quien nos tenemos por sennora e por abogada en todos nuestros fechos. e a onra e servicio de todos los Santos de la Corte Celestial qual por su piedad quiso ensalzar en fecimiento de los sus enemgios e nos escojio / por juez de su pueblo por que pudiesemos onrar e ensalzar los sus regnos e los defender e mantener e gobernar en paz e en justicia e por que todas las cosas que Dios en este mundo fiso nacer, mueren quando El tiene por bien que quanto a la vida de este mundo cada uno a su tiempo causó sabido e non / finca en cosa que fue e non aya salbo Dios que nunca ovo comienço nin avrá fin. E a semejança del ordenó los ángeles de la Corte Celestial e como quien que quiso que obiesen comienzo pero non que obiesen fin, mas que durasen por sienpre e asi como $\mathrm{El}$ es duradero asi quiso que el su Regno durase para siempre e por hende todos / los Reyes deben menbrar de aquel Regno a do an de yr a dar razón de lo que les Dios en este mundo encomendó e por quien regnan e cuyo logar tienen por lo qual son tenudos de façer limosna por el su amor e serbiçio e perteneçer al estado de los Reyes e la su realeza de enobleçer e onrar e pre/villejar a los sus vasallos que bien e lealmente le sirben heredándolos en sus regnos. Por hende queremos que sepan por este nuestro previllejo e vieren como nos Don Enrique, por la gracia de Dios Rey de Castiella, de Leó(n), de Toledo, de Gallizia, de Córdova, de M(ur)çia, de Jahe(n), del Algarbe, e Señor de Molina, reg/nante en uno con la Regna Doña Juana, mi muger, e con el Ynfante Don Joh(a)n. mio fijo primero, heredero en los nuestros regnos de Castiella e de Leó(n), conoçiendo a vos Joh(a)n Go(n)cález de Avellaneda, nuestro vasallo, los muy grandes e señalados servicios que nos façisteis e abedes fecho e façedes de cada dia e quanta lealtad e fianza fallamos en vos en todas las cosas que complieron a nuestro serviçio e aviendo voluntad de vos dar galardón de todo éllo e de vos onrar e (h)e de dar en los nuestros regnos e facer muchas mercedes agora e de aquí adelante. Por hende por vos façer bien e merced por que seades onrado e valedel mos vos e los que de vos desçendieren por que allades con que vos mantener e con que mejor nos podades serbir damos vos en donación pura e non rebocable, por juro de heredad, agora e para siempre jamás, para vos e para vuestros herederos en nuestro logar de Yscar com todas sus pertenençias e todos sus fueros / e usos e costunbres según que le perteneçen e este dicho logar de Yscar vos damos según que a nos perteneçe e según que mejor e más compldiamente lo ovieren los otros Señores cuyo fue el dicho logar fasta aqui. E damos vos lo con su fortaleza e con todas sus aldeas e términos e pertenençias e quanto ha e / debe aber asi de fecho como de derecho e con todos sus vasallos que ya moraron o moraren de aquí adelante de qualquier ley o estado o condición que sean e con todas las rentas e pechos e derechos del dicho logar asi reales como personales, foreros o non foreros e derechos de escribanias e yantares e otras qualesquier cosas / que pertenezcan en qualquier manera al Sennorio del dicho logar de Yscar e con la justiçia çevil e creminal e mero e mixto ymperio e con la justidiçión alta e baja del dicho logar de Yscar e de sus términos e con montes e valles e prados e pastos e dehesas e rios e aguas corrientes e estantes con fornos e baños / e açenas? e molinos e carneçerias e jüertas e viñas e tierras e con todas las otras cosas e pertenençias e términos que perteneçen e pueden perteneçer al dicho logar de Yscar e con todos sus fueros e franquicias e libertades que el dicho logar (ha) de los Reyes honde venimos e del Rey Don Alfon(so) nuestro padre, que Dios/perdone. e de nos e de los otros Sennores cuyo fue el dicho logar fasta aqui e que podades poner alcaldes e aguaçiles e escrivanos e otros ofiçiales qualesquier en el dicho logar quantos entendieredes e 
vieredes que son menester. E esta dicha merced e donaçión vos fazemos por juro de heredad para / agora e para sienpre jamás para vos e para vuestros fijos e vuestros herederos según que más complidamente a vos pareciere, de echo ovieron los otros sennores cuyo fue el dicho logar fata aqui para dar e vender e enpeñar e enajenar e para que fagades de éllo e en éllo todo lo que vos quisieredes asi como lo de lo vuestro / propio con que ningún de estas cosas non podades fazer con home de orden nin de religión nin de fuera del nuestro Señorio sin nuestra liçencia e sin nuestro mandado nin aún con ome alguno que sea de nuestro Sennorio que estubiere a nuestro serbiçio e retenemos para nos e a los reyes que despues de nos regnaren en Castiella y en / leó(n) mineras de oro e de plata e de otro metal si las ay e hobiere de aquí adelante e serviçios e monedas e alcabalas e todas las monedas foreras de siete en siete años quando nos las dieren los de los nuestros regnos en conoçimiento de Sennorio Real e acoyades a nos e despues de nuestros dias al dicho Ynfante Don I Joh(a)n, nuestro fijo primero heredero, e al que nos dejasemos en nuestro testamento en el dicho logar de Yscar en lo alto e en lo bajo cada que ya liegaremos con pocos o con muchos de noche e de día que fagades ende guerra por nuestro mandado cada que vos lo mandaremos o obieramos de mandar e si se menguase la justicia e que la vos non qui/sieredes façer e complir, que nos que la mandemos fazer e complir. E por este nuestro previllejo o por el traslado de el signado de escribano público mandamos al conçejo e ofiçiales e omes buenos del dicho logar de Yscar que ayan e reçiban por su Sennor de aqui adelante a vos, el dicho Joh(a)n Go(n)calez e despues de vuestros dias a / vuestros herederos e obedezcan e cunplan las vuestras cartas e vuestro mandado asi como de su Sennor e vengan a vuestros llamamientos e a vuestros enplaçamientos cada que los enbiaredes a llamar o enplaçar, e que vos recudan e fagan recudir a vos el dicho Joh(a)n Go(n)çalez o al que lo obiere de haber e de recabdar por vos o lo vuestro oviere de haber / e de heredar con todas las rentas e pechos e derechos del dicho logar e de sus términos e cada uno de ellos bien e complidamente en guisa que vos non mengue ende ninguna cosa según que más complidamente recudieron con ellos a los Reyes ende nos decimos. E al Rey Don Alfon(so), nuestro padre, que Dios perdone, e a los otros seño/res cuyo fue el dicho logar fasta aqui e por que nuestra voluntad e nuestra merced es que vos vala e que vos sea guardada esta dicha merced e docaçión de en la manera sobredicha e que nos nin ome por nos nin por nuestro mandado que vos la non tiremos nin quebrantaremos nin mandaremos quebrantar en algún tiempo por alguna manera / e despues de nuestros dias mandaremos al Ynfante Don Joh(a)n, nuestro fijo primero heredero, que vos confirme este dicho previllejio e esta merced e donaçión que vos façemos e vos la mande guardar e mantener por que para sienpre jamás sea valedera e guardada esta dicha merced e donaçión a vos e para vuestros herederos para agora e para / siempre jamás según que en este previllejo se contiene. e defendemos firmemente que ninguno nin algunos non sea osado de yr nin de pasar contra este nuestro previllejo e esta merced e donaçión que vos façemos por vos la quebrantar o menguar en alguna cosa o en algún tiempo por alguna manera. Si non qualquier o qualesquier que lo fi/çiesen abrian la mi yra e demás pecharme ya en pena de mil madaveries de la buena moneda cada uno que contra ello fuese e a vos el dicho Joh(a)n Go(n)çalez o a vuestros herederos todo los daños e menos cabos que por hende reçibieredes doblados e desto vos mandamos dar este nuestro previllejo rodado e sellado con nuestro sello de plo/mo colgado. Dado en las Cortes de Toro, veinte dias de Setienbre, era de mil e quatrocientos e nueve años. E agora el dicho Joh(a)n Go(n)çalez pidionos por merced que le confirmarernos el dicho privillegio e donaçión que el dicho Rey, nuestro padre, le fiso e que lo mandasemos guardar en todo según que en él se contiene. E nos el sobredicho Rey Don IOAN, por façer bien e merced al dicho Joh(a)n Go(n)çalez de Abellaneda tobimos por bien e confirmamosle dicho previllejo e donaçión que el dicho Rey, nuestro padre, le fizo e mandamos que le vola e le sea guardado a él e a los que del vinieren 
e lo suyo hovieren de heredad / e su vos tovieren en todo bien e complidamente según que en èl se contiene e fagan que mejor e más complidamente le fue guardado en tiempos del dicho Rey Don Enriq(ue), nuestro padre, que Dios perdone, e en el nuestro fasta aqui e defendemos firmemente que ninguno nin algunos non sean osados de le/yr e pasar contra el dicho previllejo nin contra parte del por gelo quebrantar nin menguar cosa en algún tiempo, por alguna manera so la pena que en el dicho previllejo se contiene e qualquier o qualesquier que ello fuesen o pasasen avrán la nuestra yra y pecharmos ya en pena de mil / madaveries de la buena moneda e al dicho Joh(a)n Go(n)çalez e a sus herederos e a quien lo suyo obiere de heredar o a quien su voz toviere, todos los daños e menoscabos que por esta raçón reçibiesen doblados e porque ésto sea firme e estable para siempre jamás, mandamos dar este nuestro pevillejo signado e se/llado con nuestro sello de plomo colgado. Fecho el privillejo en las Cortes que nos fezimos en la muy noble cibdad de Burgos, ocho dias de Agosto, era de mil quatrocientos e diez e siete años. Johanes Rex. Yo Loys $F(e) r n(a n d) e z$ la fiçe escribir por mandado del Rey. Joh(a)n F(e)rr(ande)z. E agora por vos façer merced e por tenigades con que mejor vos mantener $\mathrm{e}$ valedes más e que seades más honrado nos podades más bien servir, e considerando con quanta aliança e fidelidad nos abedes servido e que dello meresçedes galardón e emienda remuneraçión de vuestros serviçios, vos confirmamos la merced sobredicha que el sobredicho Rey Don Enrri/que, nuestro padre, vos fiço e la que por nos, vos a sido confirmadada e mandado guardar e ya dello vos façemos merced, gracia e donaçión pura e non rebocable para siempre jamás de las alcabalas e terçias e portazgos e demás pechos que a nos perteneçen o perteneçer deban por qualquier razón reservando sólo para nos / la superporpiedad perteneçiente a nuestra realeza e demás cosas que de elia non se pueden apartar para lo que ayades $e$ tengades de aqui adelante e goçedes como propio vuestro, vos e vuestros fijos e herederos o quien vuestro dinero o el suyo hobiere por juro de heredad para agora e para siempre jamás e para lo que podades donar, trocar, / bender o canbiar como cosa libre vuestra e propia e fagades en ella todo lo que vos quisieredes así como de lo vuestro propio con que ninguna destas cosas non podades façer nin fagades con omes de orden nin de religión nin de fuera de nuestros Regnos e Sennorios nin con home que nos aya de servicio sin nuestra liçencia e mandado. E mandamos / a los adelantados, merinos e demás menistros e justicias de estos nuestros Regrios e Señorios que vos guarden e fagan guardar esta merced que vos feçimos e la que vos fiço el Rey Don Enriq(ue), nuestro padre, e defendemos firmemente que alguno nin algunos non sean osados a vos yr contra ella ni contra parte della por vos la men/guar en manera nin en tiempo alguno so pena qualquier lo fiçiese abria la nuestra yra e pegarme ya mil doblas castellanas e a vos el dicho Joh $(a) n$ Go(n)çalez o a vuestros herederos las costas, dagnos e menoscabos que por hende recibieredes doblados e desto vos mando dar este nuestro privillejo rodado e sellado con nuestro sello de plomo colgado. / Fecho el privillejo en las Cortes que nos fezimos en la muy noble cibdad de Burgos, veynte e cinco dias de Agosto, era de mil e quatrocientos e diez e siete años. E nos el sobredicho Rey Don IOAN, regnante en uno con la Regna Doña LEONOR, mi muger, en Castiella, en Leó( $n)$, en / Toledo, en Gallizia, en Sevilla, en Córdova, en M(ur)çia, en Jahe $(n)$, en Baeça, en Badajoz, en el Algarbe, en Algeçira, en Lara, en Vizcaya, en Molina, otorgamos este previllejo e confirmamoslo

El Infante Don Donis, fijo del Rey de Portugal e Sennor de Alva de Torm(e)s, vasallo del Rey ... Confirma. Don Fadriq(ue), Duque de Banave(n)te, hermanos del Rey ... Confirma.

Don Alfon(so), hermano del Rey, Conde de Norena ... Contirma. Don Pedro, primo del Rey, Conde de Trastámara e Señor de Lemos, de Sarria ... Confirma. 
Don Alfon(so), fijo del Infante Don P(er)o (de Aragón), Marqués de Villena, Conde de Ribagorza, de Den(i)a, vasallo de Rey ... Confirma. Don Beltra(n) de Elaq(uin) Condestable de Francia, Vasallo del Rey ... Confirma

(Encima del signo radado)

Don Pedro, Arzobispo de Toledo, Primado de las Españas

Confirma

(Signo Rodado: Rueda dividida en cuatro cuarterones con los dos castillos y los dos leones dela corona de Castilla). Signo del Rey Don Iohan. El Conde Don Sancho, Alférez. Alvar Garcia, Mayordomo.

\section{COLUMNA:}

Don Ferra(n)do, Arzobispo de Sevilla

Don Domi $(n) g o$, Obispo de Burgos

Don , Obispo de Pale(n)cia

Don Gonçalo, Obispo de Calahorra

Don Joh(a)n, Obispo de Sigue(n)ça, Chanceller Mayor de Rey ......

Don , Obispo de Osma

Don Hugo, Obispo de Segovia

Don Alfon(so), Obispo de Ávila

Don Nicolás, Obispo de Cue $(n) c a$

Confirma

Confirma

Confirma

Confirma

Confirma

Confirma

Confirma

Confirma

Confirma

Don Pedro, Obispo de Plase(n)cia

Confirma

Don Pedro, Obispo de Córdova

Confirma

Don Nicolás, Obispo de Ca(rta)jena

Don Joh(a)n, Obispo de Jahe(n)

Confirma

Don Ximeno, Obispo de Calis

Confirma

Confirma

\section{COLUMNA}

Don Joh(a)n Sanch(e)z Manuel, Conde de Carrión, Adelantado Mayor del Regno de Murçia

Don Bernald(o) de Bearne, Conde de Medina, Vasallo del Rey ......

Don Diego Gómez Ma(n)riq(ue)

Don Joh(a)n Rodrig(ue)z de Castañeda

Don Joh(a)n Rodrig(ue)z de Villalobos

Don Joh(an) Ramir(e)z de Arellano, Sennor de los Cameros, Vasallo del Rey

Don Belnal de Guevara, Vasallo del Rey

Sancho F(e)rr(ande)z de Tovar, Guardia Mayor del Rey

Don Arnao, Sennor de Villalpa(n)do, Vasallo del Rey

Don Joh(a)n M(artine)z de Luna, Vasallo del Rey

Don Nuño $N(u \tilde{n} e) z$ de Aça

Alvar(e)z de Aça

Confirma

Contirma

Contirma

Confirma

Contirma

Contirma

Confirma

Confirma

Confirma

Confirma

Confirma

Confirma

III COLUMNA:

Don Rod(ri)go, Arzobispo de Sa(n)tiago, Notario Mayor del Regno de $L e o ́(n)$

Don Rod(ri)go, Obispo de Leó(n)

Don Gutierre, Obispo de Oviedo

Don Alfon(so), Obispo de Astorga

Don M(atin). Obispo de Camora

Don Álvaro, Obispo de Salama(n)ca

Don Alton(so), Obispo de Cibdat

Don Ferra $(n)$ do, Obispo de Coria

Don Ferr $(n)$ do, Obispo de Badajoz

Don Fra(n)cisco, Obispo de Mo(n)deñedo
Confirma

Confirma

Confirma

Confirma

Confirma

Confirma

Confirma

Confirma

Confirma

Confirma 
Don Joh(a)n, Obispo de Tuy

Contirma

Don Garcia, Obispo de Orens(e)

Confirma

Don Pedro, Obispo de Lugo

Confirma

IV COLUMNA:

Don Joh(a)n Alfon(so) de Guzm(an), Conde de Niebla

Confirma

Don Po(n)çe de Leó(n)

Don Alvar P(ere)z de Guzm(an)

Don P(er)o de Villes, Conde de Ribadeo, Vasallo del Rey

Confirma

Contirma

Confirma

Don Alfon(so) Tellez de Giro(n)

Confirma

Don P(er)o Alfon(so) de Giró(n)

Confirma

Don Alfon(so) F(e)rr(andez) de Mo(n)temayor. Adelantedo de la

Frontera

Confirma

Don Gonçalo F(e)rrandez de Aguilar

Confirma

(Debajo de la primera columna de confirmantes aparece separado)

Don P(er)o F(e)rr(ande)z de Velasco, Camarero Mayor del Rey ....

Don P(er)o Ma(n)rriq(ue)z, Adelartado Mayor de Castilla

Confirma

Confirma

(Debajo del signo rodado)

Jua(n) Nuñ(e)z de Villaza(n), Justicia Mayor de casa del Rey

Confirma

Don Ferra(n)t Sanch(e)z de Tovar, Almirante Mayor de la mar ......

Confirma

Diego Lop(e)z Pacheco, Notario Mayor de Castilla ...

Confirma

P(er)o Suar(e)z de Toledo, Notario Mayor del Regno de Toledo ....

Confirma

$P(e r) o$ Suar(ez) de Guzma(n), Notario Mayor de Andaluzia

Confirma

(Debajo de la III columna)

Don Ferrant Osorez, Maestre de la Cavalleria de Sa(nti)ago

Confirma

P(er)o Ruys Sarmie(n)to, Adelantado Mayor de Gallizia

Confirma

(Debajo de la IV columna)

Pier)o Muñiz, Maestre de la Orden de Calatrava

Confirma

El Prior de Sant Joh(a)n

Confirma

P(er)o Suar(e)z de Q(ui)ñon(e)s, Adelantado Mayor de la Tierra de Leó(n)

Contirma

Don Pedro, Obispo de Plasencia, Notario Mayor del Rey de los privillejos rodados, lo mandó dar en el dia primero que el Rey sobredicho Don Joh(a)n regnó e se coronó Rey en Castiella.

P(er)o Loys $F(e) r r(a n d e) z$ escrivano del Rey lo fizo escribir.

(Rúbrica) Yo, el Rey (Rúbrica)

(Rúbrica) Loys Ferrandez (Rúbrica) 